\title{
Distribución espacial y controles ambientales de las represas (tajamares) en el Chaco Árido
}

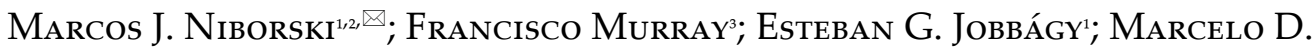 \\ Nosetto $^{1,4}$; Pedro D. Fernández ${ }^{5,6}$; George Castellanos ${ }^{1}$ \& Patricio N. Magliano ${ }^{1,7}$ \\ ${ }^{1}$ Grupo de Estudios Ambientales-IMASL, Universidad Nacional de San Luis (UNSL) y CONICET. San Luis, Argentina. \\ ${ }^{2}$ Cátedra de Manejo y Conservación de Suelos, Facultad de Agronomía, Universidad de Buenos Aires (UBA). CABA, \\ Argentina. ${ }^{3}$ INTA, AER San Luis. San Luis, Argentina. ${ }^{4}$ Cátedra de Climatología, Facultad de Ciencias Agropecuarias, \\ Universidad Nacional de Entre Ríos (UNER). Entre Ríos, Argentina. ${ }^{5}$ Instituto de Ecología Regional, CONICET y \\ Universidad Nacional de Tucumán. Tucumán, Argentina. ${ }^{6}$ Departamento de Biogeoquímica, Instituto de Investigación Animal \\ del Chaco Semiárido, INTA. Tucumán, Argentina. ${ }^{7}$ Departamento de Biología, Facultad de Química, Bioquímica y Farmacia, \\ Universidad Nacional de San Luis (UNSL). San Luis, Argentina.
}

\begin{abstract}
Resumen. Las regiones áridas tienen déficit hídrico a lo largo de todo el año, lo cual limita el crecimiento de la vegetación y la provisión de agua para bebida animal. El Chaco Árido ( 10 Mha) sostiene una producción ganadera extensiva de baja inversión, basada en cosechar agua de lluvia en represas (tajamares) como principal fuente de abastecimiento de agua. En este trabajo se determinó la distribución espacial de las represas y su relación con el entorno biofísico (precipitación, vegetación, caminos) en el Chaco Ârido. Para ello analizamos imágenes satelitales, información vectorial y análisis multivariados sobre una grilla de 135 celdas de $0.25^{\circ} \times 0.25^{\circ}$ cada una. En total identificamos 7920 represas (1 cada 1230 ha) y observamos densidades máximas de 1 represa cada 185 ha, pero también celdas sin represas, asociadas a la presencia de sierras, salinas y dunas. La densidad de represas fue mayor en celdas con mayor densidad de establecimientos ganaderos, caminos y carga animal $(\mathrm{r}=0.63, \mathrm{r}=0.56$ y $\mathrm{r}=0.51$, respectivamente; $\mathrm{P}<0.01$ en todos los casos $)$, y en sitios con mayor precipitación media anual y menor variabilidad interanual $(r=0.62$ y $r=-0.47$, respectivamente; $P<0.01$ para ambos casos). Aunque la precipitación media anual fue el atributo que mejor se asoció a la distribución de las represas a escala regional, dicha relación fue más variable hacia los extremos del gradiente (árido y subhúmedo). Esto puede deberse a factores antrópicos tales como la baja rentabilidad de los sistemas ganaderos y la historia o el cambio en el uso del suelo. Los resultados de este trabajo representan un primer intento para dimensionar la importancia que tienen las represas en el Chaco Árido. Consideramos que este estudio puede ser útil para entender la producción ganadera y también para futuras investigaciones relacionadas con la conservación de la vida silvestre y el desarrollo de poblados rurales en la región.
\end{abstract}

[Palabras clave: tajamar, ecohidrología, escurrimiento superficial, semiárido, bosque seco, bebida animal]

Aвstract. Spatial distribution and environmental controls of dams (small impoundments) in the Arid Chaco. Arid regions are characterized by water shortage throughout the year, which constrains both the vegetation growth and the supply of water for livestock consumption. The Arid Chaco ( 10 Mha) hosts extensive and low-investment livestock systems based on rainwater harvesting stored in dams (small impoundments) as the main source of water supply. In this study, we characterized the spatial distribution of dams in the Arid Chaco and analyzed their relationship with biophysical variables (e.g. rainfall, vegetation, roads). For these purposes, we used satellite images, vector information and performed multivariate analysis on a spatial grid of 135 cells of $0.25^{\circ} \times 0.25^{\circ}$. In total, 7920 dams were identified ( 1 dam every 1230 ha), with maximum densities of 1 dam every 185 ha but also cells without dams associated with the presence of mountains, salt flats and dunes. Dam density was higher in cells with higher densities of livestock establishments, roads and cattle stock $(\mathrm{r}=0.63$, $\mathrm{r}=0.56$ and $\mathrm{r}=0.51$, respectively; $\mathrm{P}<0.01$ in all cases), and in cells with higher mean annual rainfall and lower interannual rainfall variability ( $\mathrm{r}=0.62$ and $\mathrm{r}=-0.47$, respectively; $\mathrm{P}<0.01$ for both cases). Although the mean annual rainfall was the best-associated variable with the distribution of dams at the regional scale, this relationship weakened towards the extremes of the gradient (arid and sub-humid). This may be due to anthropic factors such as the low profitability of livestock systems, the previous land uses or land-use changes. The results of this study represent a first attempt to assess the importance of impoundments in the Arid Chaco. We believe that this study may be useful not only to understand livestock production, but also for future studies related to the conservation of wildlife and the development of rural towns in the region.

[Keywords: impoundment, ecohydrology, runoff, semi-arid, dry forest, animal drink]

Editora asociada: Patricia Kandus

marcosniborski@gmail.com
Recibido: 26 de Junio de 2021

Aceptado: 15 de Diciembre de 2021 


\section{INTRODUCCIÓN}

El planeta experimenta cambios muy profundos en lo que respecta a la circulación global del agua (Jackson et al. 2001; Pellegrini and Fernández 2018; Syvitski et al. 2020). Por un lado, el área continental terrestre ocupada por desiertos y semidesiertos ha aumentado del 41 al $45 \%$ en la última década, y se proyecta un incremento aún mayor (Feng and Fu 2013; Huang et al. 2016). Por otro lado, las predicciones para regiones áridas y semiáridas, basadas en modelos de circulación global de agua, sugieren aumentos en el largo y la intensidad de los períodos de sequías interrumpidos por lluvias de gran intensidad (IPCC 2014; Prăvălie 2016). Finalmente, la presión del crecimiento poblacional de las ciudades y sus mercados sobre la demanda de alimentos, maderas, fibras, entre otros bienes, conlleva a la intensificación de los sistemas productivos existentes, con consecuencias ambientales muchas veces poco deseables (e.g., arbustización, erosión, desertificación) (Lal 2004; Zika and Erb 2009; Bestelmeyer et al. 2015). En los sistemas áridos y semiáridos, donde la disponibilidad de agua es el factor más limitante para la vida y los usos, la cosecha de agua de lluvia representa una opción valiosa en términos económicos, sociales y ambientales (Oweis and Hachum 2009a; UNEP 2009). Esta tecnología permite amortiguar los impactos de la variabilidad climática y aumentar las posibilidades de vida y las capacidades productivas de dichos sistemas (Godfray et al. 2010; Rockström and Falkenmark 2015).

En planicies áridas y semiáridas, la combinación de una baja precipitación media anual, drenaje profundo infrecuente (o nulo) y una gran cantidad de sales acumuladas en el perfil del suelo, determina que las napas freáticas se encuentren profundas o tengan altos contenidos de sales (Scanlon et al. 2005; Contreras et al. 2013; Giménez et al. 2020). Si bien representa un flujo menor del balance de agua de estas regiones, el escurrimiento superficial en muchas ocasiones es la única fuente de abastecimiento de agua líquida para personas y animales (Evenari et al. 1971; Lavee et al. 1997; Hoff et al. 2010). Cosechar y almacenar esa pequeña fracción de agua líquida que ofrece el escurrimiento superficial fue la clave para que se asentaran y se desarrollaran muchas comunidades humanas en regiones áridas y semiáridas del planeta a lo largo de la historia (Vohland and Barry 2009; Kahinda and Taigbenu 2011;
Biazin et al. 2012). Existen registros de sistemas de cosecha de agua de lluvia de más de 6000 años, y se especula que esa práctica pudo ser practicada, incluso, en tiempos prehistóricos (Lavee et al. 1997; Mbilinyi et al. 2005; Denison and Wotshela 2012). En el proceso de cosecha de agua de lluvia se pueden reconocer tres pasos: la captación y el transporte sobre la superficie del terreno, el almacenamiento en reservorios superficiales o subterráneos y la distribución y el uso para fines productivos o domésticos (Ngigi 2003; Oweis and Hachum 2009b).

Los sistemas ganaderos pastoriles ocupan un papel protagónico en el desarrollo productivo de las regiones áridas y semiáridas, pero también impactan fuertemente sobre la ecohidrología de dichas regiones (Thornton 2010; Asner et al. 2004). Entender la intensidad de uso, la eficiencia y la estabilidad de sistemas ganaderos pastoriles continúa siendo uno de los mayores desafíos para estudios de escala regional (Erb et al. 2016). Mientras que el registro de información espacial de cultivos o áreas irrigadas abunda en muchas regiones del planeta, la información espacialmente explícita sobre sistemas ganaderos es escasa y errática, lo cual aumenta la incertidumbre en las predicciones que de ellos derivan (Kuemmerle et al. 2013). Asimismo, los esfuerzos realizados para entender el funcionamiento de sistemas ganaderos a escala de región se concentraron casi exclusivamente en estimar la productividad primaria neta aérea de los recursos forrajeros (McNaughton et al. 1989; Paruelo et al. 1997; Blanco et al. 2009). En regiones áridas resulta indispensable complementar dichos esfuerzos con el dimensionamiento de la oferta hídrica que ofrece el paisaje en lo que respecta a su acceso, estabilidad y capacidad de uso.

El Chaco Árido es una de las regiones ganaderas de mayor extensión ( 10 Mha) y menor desarrollo tecnológico de Sudamérica (Rueda et al. 2013; Fernández et al. 2020; Karlin et al. 2013). La actividad ganadera es posible gracias a la cosecha y el almacenamiento de agua de lluvia en represas o tajamares (Umazano et al. 2004; Magliano et al. 2015b). Dado que estas represas son la tecnología de abastecimiento de agua para el ganado más difundida en la región, resulta clave conocer qué factores ambientales determinan su distribución en el territorio.

El objetivo general de este trabajo fue caracterizar la distribución espacial de los 
sistemas de cosecha de agua delluvia (represas) y su asociación con variables biofísicas en el Chaco Árido. Específicamente, buscamos a) cuantificar, mapear y estimar la densidad de represas en la totalidad de la región ( 10 Mha), y b) determinar la asociación entre la densidad de represas y algunas variables biofísicas vinculadas al ambiente y al uso ganadero (e.g., lluvia, vegetación, relieve, índices ganaderos). De estos objetivos específicos derivan las dos hipótesis que guiaron nuestro estudio. Hipótesis 1: la densidad de represas no es homogénea en la región. Nuestra predicción es que habrá zonas con mayor densidad de represas que otras, e incluso, zonas sin represas. Esto se debería a la heterogeneidad de la expresión de factores biofísicos y antrópicos. Hipótesis 2: la precipitación es la variable que se asocia en mayor medida con la distribución de las represas, siendo poco relevantes otros atributos del ambiente en la distribución espacial de las mismas. Nuestra predicción es que las zonas con mayor precipitación media anual presentarán una mayor densidad de represas. Esto se debería a que, en zonas más lluviosas, la mayor oferta forrajera permite mayores cargas animales lo que conlleva una mayor demanda de agua de bebida.

\section{Materiales y MÉtodos}

\section{Área de estudio}

El Chaco Árido cubre el noroeste de la provincia de San Luis, el centro y sur de La Rioja y una porción menor de Córdoba, Catamarca, Santiago del Estero, San Juan y Mendoza (Oyarzabal et al. 2018) (Figura 1 a). Esta región pertenece al dominio chaqueño;
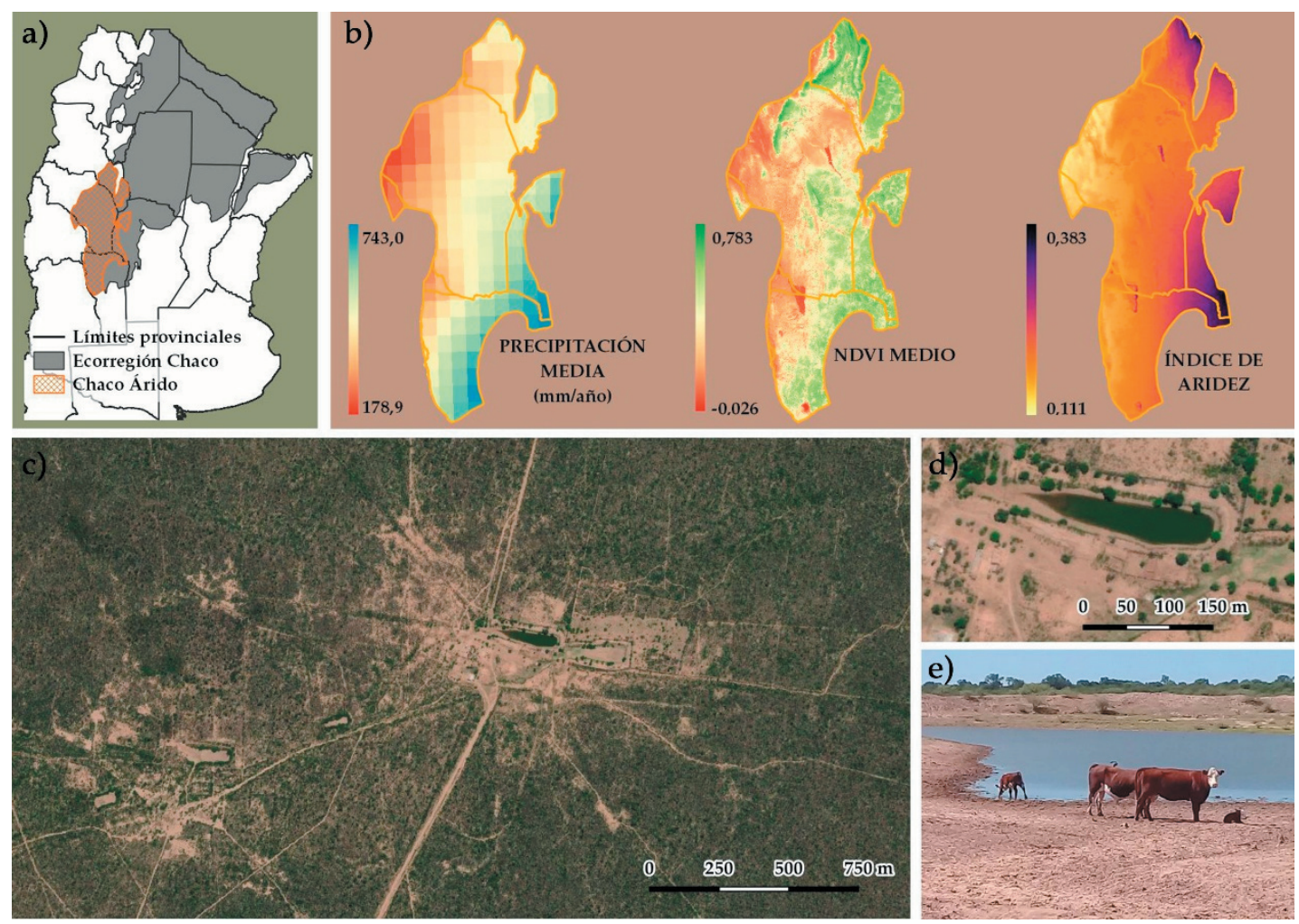

Figura 1. Caracterización de la región y de los sistemas estudiados. a) Ubicación geográfica del Chaco Árido (naranja rayado) dentro de la provincia fitogeográfica del Chaco (gris lleno). b) Izquierda: precipitación media anual del período 2000-2019 basado en imágenes TRMM (Tropical Rainfall Measuring Mission). Centro: índice de vegetación promedio anual correspondiente al período 2000-2019 elaborado en base al producto de los sensores Modis, MOD13Q1 y MYD13Q1. Derecha: índice de aridez medio anual extraído de Global-AI_ET0 (Trabucco 2019). c) Paisaje típico de la región captado en una imagen satelital de alta resolución espacial ESRI. d) Detalle de una represa observada en (c). e) Fotografía de una represa tomada en el campo.

Figure 1. Characterization of the region and studied systems. a) Geographic location of the Arid Chaco (striped orange) within the phytogeographic province of Chaco (solid gray). b) Left: mean annual rainfall for the period 2000-2019 based on TRMM (Tropical Rainfall Measuring Mission) images. Center: mean annual vegetation index corresponding to the period 2000-2019 based on Modis products MOD13Q1 and MYD13Q1. Right: mean annual aridity index extracted from Global-AI_ET0 (Trabucco 2019). c) Typical landscape of the region captured in an ESRI high-spatial resolution satellite image. d) Zoom-in of a dam observed in (c). e) Photograph of a dam taken in the field. 
se encuentra rodeada por las subregiones del Chaco Semiárido al norte y el Chaco Serrano al este, por la provincia fitogeográfica de Monte al oeste y por el Espinal al sureste (Karlin et al. 2013). El presente trabajo se basó en los límites establecidos por Oyarzabal et al. (2018), que representan una actualización de los determinados por Cabrera et al. (1976), con numerosas validaciones empíricas por parte de la comunidad científica desde 2018 hasta la actualidad. El balance hídrico en la región es negativo para todos los meses del año, con medias anuales entre 0.3 y 0.6 (índice de aridez: cociente entre la precipitación anual y la evapotranspiración de referencia anual) (Blanco et al. 2008; Fernández et al. 2020). Las precipitaciones se concentran en los meses de verano (50\% de la lluvia anual ocurre entre diciembre y febrero) (Magliano et al. 2015) y se observa un gradiente creciente de las mismas de noroeste a sureste (rango: 180-743 mm/año), que coincide con cambios en la vegetación y con los límites máximos y mínimos del índice de aridez explorados en la región (Llano 2018; Karlin et al. 2013; Peña Zubiate et al. 1998) (Figura 1b).

La fisiografía del Chaco Árido está constituida por valles y llanuras producto del depósito eólico de sedimentos loéssicos del cuaternario desde la cordillera de los Andes y el modelado aluvial (Pennington et al. 2000; Tripaldi et al. 2013). Los suelos, a veces salinizados, son algo excesivamente drenados, de escaso desarrollo, clasificados taxonómicamente en el orden de los Entisoles (Iriondo 1993; Peña Zubiate et al. 1998; Kirby et al. 2001; Moretti et al. 2019). Con pendientes generales menores al $1.5 \%$, la hidrografía está compuesta por cuencas autóctonas y endorreicas, y grandes extensiones sin presencia de cursos ni cuerpos de agua permanentes. La disponibilidad de agua subterránea en los estratos superiores del suelo (a los cuales pueden acceder las raíces de la vegetación) es prácticamente nula en toda la región (Karlin et al. 2013). En términos generales, la napa freática se encuentra por debajo de los $30 \mathrm{~m}$ en gran parte del territorio, a excepción de las áreas topográficamente más deprimidas de la región (8-10\% de la superficie total) (Karlin et al. 2013). En estos casos, la napa aflora en superficie y genera salinas como resultado del aporte de agua subsuperficial, con recarga de acuíferos en las sierras circundantes, y el balance hídrico negativo local (Coirini et al. 2010).

La vegetación nativa actual se compone de especies xerófitas dispuestas en bosques abiertos y estepas arbustivas (García et al. 2017; Fernández et al. 2019). El estrato arbóreo está compuesto principalmente por Prosopis flexuosa y Aspidosperma quebracho-blanco, y el arbustivo por Larrea divaricata y Senna aphylla (Bogino and Bravo 2014; García et al. 2017; Magliano et al. 2019b). Sin embargo, en los últimos 30 años se registraron cambios en la cobertura vegetal a partir de la introducción de pasturas megatérmicas (subtropicales) como Cenchrus ciliaris y Eragrostis curvula, y algunas zonas irrigables con cultivos agrícolas como Sorghum spp., Zea mays y Glycine max (Blanco et al. 2005; Quiroga et al. 2009a; Marchesini et al. 2015). La principal actividad productiva de la región es la ganadería extensiva, mayormente la cría bovina de terneros con baja carga animal (10 a 40 ha por animal) (Karlin et al. 2013), dada la baja receptividad forrajera de la vegetación nativa. Sin embargo, en algunas situaciones más tecnificadas se incorporan pasturas de mayor valor forrajero a partir de rolados para aumentar la carga animal.

\section{Las represas del Chaco Árido}

La gran mayoría de las represas se construyen excavando en una superficie aproximada de $100 \mathrm{~m}$ de largo por $50 \mathrm{~m}$ de ancho, con una profundidad máxima hacia un extremo de hasta 4 m (Fernández Duque 1988). El material extraído se deposita en el perímetro del área de almacenamiento, delimitando un terraplén en forma de U o herradura (Basán Nickisch 2010). La sección abierta del terraplén se orienta hacia el sector topográficamente más alto del terreno para facilitar el ingreso de agua de escurrimiento superficial (Basán Nickisch 2013; Magliano et al. 2019a) (Figura 1c, d y e). Originalmente, las represas eran construidas con herramientas 'de mano' traccionadas por mulas o bueyes; luego, la incorporación de maquinaria agrícola y vial facilitó su construcción y mantenimiento (Greslebin 1931; Fernández Duque 1988). El peso de las maquinarias que se usan hoy favorece el proceso de compactación del suelo, lo cual disminuye el flujo de pérdida de agua de la represa por infiltración (Fernández Duque 1988). No obstante, la presencia de suelos excesivamente drenados por el alto contenido de arenas gruesas, así como la presencia de sales o rocas en superficie, dificulta la capacidad de almacenar agua. De esta manera, las represas funcionan como pequeñas lagunas artificiales que desacoplan la oferta hídrica de la lluvia concentrada en los meses de verano (Basán Nickisch 2010; Magliano et al. 2015b). 
Una característica que diferencia a las represas de otras fuentes de abastecimiento de agua (e.g., tanques australianos) es que su funcionamiento hidrológico se encuentra afectado por el comportamiento y los hábitos del ganado vacuno (D'Odorico et al. 2013; Lundgren et al. 2021). En general, el ganado ingresa al interior de las represas para acceder directamente al agua, demarcando un área próxima a la represa denominada 'área de sacrificio' o 'piósfera' (Lange 1969; Graetz and Ludwig 1976; Macchi and Grau 2012; Chillo et al. 2015). Esta zona, que suele cubrir entre 0.5 y 3 ha de superficie, se caracteriza por tener escasa cobertura vegetal y alta compactación del suelo como resultado del sobrepastoreo y del pisoteo animal (Todd 2006; Manthey and Peper 2010). Además de generar la piósfera, el tránsito ganadero por la matriz de la vegetación nativa crea una red de senderos topográficamente deprimidos y con baja tasa de infiltración que convergen en la represa (Heshmatti et al. 2002; Blanco et al. 2008; Blanco et al. 2009). Estos senderos, que pueden tener hasta $5 \mathrm{~km}$ de longitud, podrían generar la conectividad del paisaje necesaria para transportar agua de escurrimiento en eventos de lluvia grandes e intensos desde zonas alejadas a la represa (Moreno-de las Heras et al. 2011; Basant et al. 2020; Saco et al. 2020). La formación de estos senderos resulta de 1) las distancias largas que debe caminar el ganado vacuno para acceder al escaso forraje de calidad que ofrece la vegetación nativa, y 2) la escasa fracción del suelo transitable debido a la gran densidad de arbustos espinosos (Anriquez et al. 2005; Blanco et al. 2005; Bogino and Bravo 2014). De esta forma, la presencia de la represa en una matriz boscosa representa mucho más que un simple cuerpo de agua. Esto se debe a que la mayor conectividad generada por el tránsito del ganado altera la ecohidrología en una fracción del paisaje mucho mayor que la que ella ocupa.

\section{Relevamiento satelital de represas}

Para realizar el relevamiento de represas en toda la región se partió de reconocimientos previos realizados en dos sub-áreas del Chaco Árido, aportados por investigadores de la Estación Experimental Agropecuaria de INTA de La Rioja (EEA La Rioja) y de la Agencia de Extensión Regional de INTA de San Luis (AER San Luis). Los reconocimientos se elaboraron en base a la interpretación visual de imágenes satelitales de alta resolución espacial provistas por los servidores de Google, Bing y ESRI, correspondientes al cuadrante noroeste de San Luis (17813 km²; 2068 represas) (Magliano et al. 2015) y a una porción mayoritaria de los Llanos Riojanos (4844 km²; 534 represas), respectivamente (datos sin publicar) (Figura 2a).

A fin de generar una herramienta que permita generalizar la identificación de represas (espejos de agua de entre 1000 y $10000 \mathrm{~m}^{2}$ ) se extrajeron los valores del índice diferencial de agua normalizado (NDWI, por su sigla en inglés), que se usa como estimador de la presencia de los cuerpos de agua a partir de la colección de represas identificadas visualmente (McFeeters 1996). Dicho estimador se elaboró con las bandas del verde y del infrarrojo cercano (NIR, por su sigla en inglés), correspondientes a imágenes Sentinel 2A para el período 2017-2020.

$$
\mathrm{NDWI}=(\text { verde }-\mathrm{NIR}) /(\text { verde }+\mathrm{NIR})
$$

Las imágenes provistas por Sentinel 2A tienen una resolución espacial de $10 \mathrm{~m}$ en las bandas del visible y del NIR, con un período de revisita aproximado de 5 días para estas latitudes. Esto hace posible identificar objetos con superficies de al menos $100 \mathrm{~m}^{2} \mathrm{y}$ caracterizar su variabilidad temporal.

A partir de los valores de NDWI calculados sobre las represas de las sub-áreas con reconocimiento visual previo se calcularon las medias, mínimos, máximos y coeficientes de variación temporal de dicho índice para cada represa. Se estableció como umbral mínimo de NDWI para la detección de represas de toda la región el valor de -0.12; es decir, todos los pixeles con valores de NDWI0.12 se clasificaron como represas. Dicho umbral surge de un análisis de sensibilidad realizado sobre un rango de umbrales desde -0.20 hasta 0.09 y cuya variable respuesta fue el número de aciertos verdaderos (luego de haber eliminado los falsos positivos). Una vez definido dicho valor umbral, se realizaron clasificaciones bimestrales con el objeto de identificar la presencia de espejos de agua. De la sumatoria de todas las ocurrencias se definió el área bimestral máxima y la recurrencia de los mismos. En la imagen resultante se vectorizaron las represas identificadas y se extrajeron los centroides correspondientes a cada una de ellas. Los errores de comisión o falsos positivos, asociados con el efecto confundido de nubes y sombras, fueron eliminados mediante la interpretación 
a)

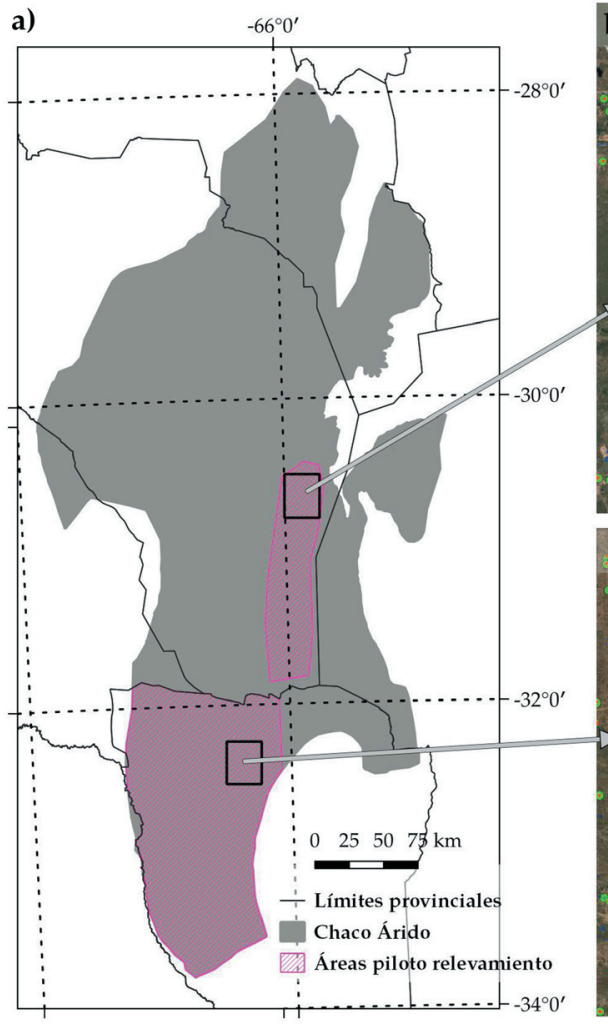

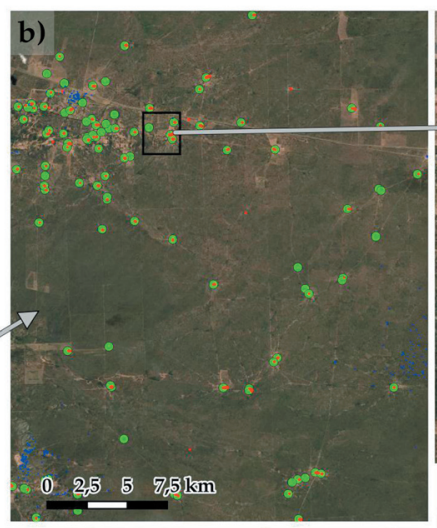

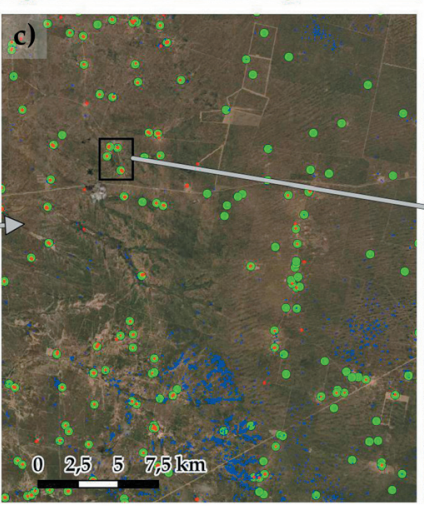

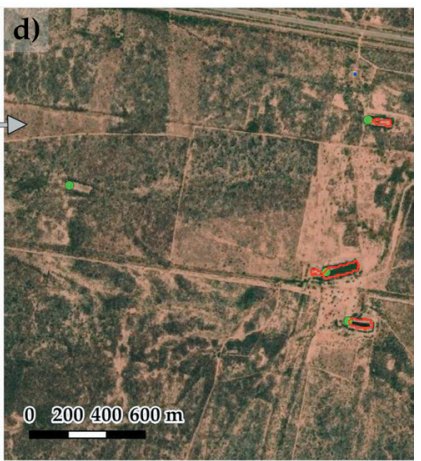

- Represas observadas

$\square$ Represas (NDWI >-0,12)

$\square$ Errores de comisión (NDWI>-0,12)

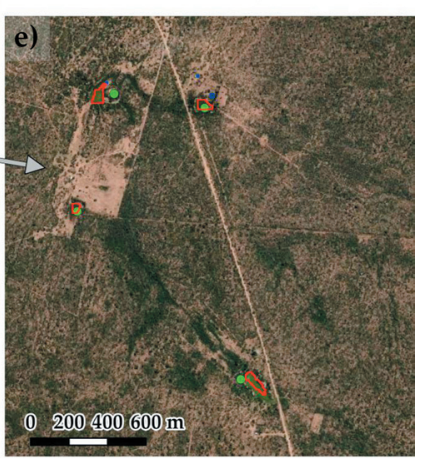

Figura 2. Relevamiento satelital de represas. a) Área de estudio (Chaco Árido, resaltado en gris) y áreas piloto de detección de represas por medio de observación (rayado magenta). b) y c) Detalle de los objetos identificados en el relevamiento en ambas áreas (imágenes ESRI de alta resolución). Represas observadas (puntos verdes), represas extraídas de la clasificación de NDWI elaborado en base a Sentinel 2A (mayor a -0.12; polígonos rojos) y errores de comisión de la clasificación de NDWI (polígonos azules). d) y e) Se muestra la misma información que en b) y c), respectivamente, pero con mayor detalle espacial.

Figure 2. Satellite survey of dams. a) Study area (Arid Chaco, highlighted in gray) and pilot areas for detecting dams through observation (magenta striped). b) and c) Detail of the objects identified in the survey in both areas (highresolution ESRI images). Observed dams (green dots), dams extracted from Sentinel 2A-based NDWI classification (greater than -0.12; red polygons) and NDWI classification commission errors (blue polygons). d) and e) The same information presented in b) and c), respectively, but with higher spatial resolution.

visual de las imágenes (Figura $2 b, c, d$ y e). Posteriormente, para las represas detectadas a partir del NDWI se calculó un porcentaje de error de omisión del 30\% sobre el total de represas. Una vez mapeadas las represas del Chaco Árido a partir del NDWI, por un lado, se contabilizó y se calculó la densidad en función de la superficie que abarca cada provincia en el Chaco Árido. Por otro lado, se utilizó una grilla de 196 celdas, construidas en base a la matriz de las imágenes de precipitación del producto satelital Tropical Rainfall Measuring Mission (TRMM 3B43) para representar con mayor resolución la variabilidad de la distribución espacial de las represas a lo largo y ancho de la región. La resolución espacial de TRMM es $0.25^{\circ} \times 0.25^{\circ}(\sim 28 \mathrm{~km}$ en latitudes cercanas al ecuador) (Figura 3).

\section{Análisis multivariado}

Se recolectó información referida a factores antrópicos y biofísicos para evaluar su grado de asociación con la distribución espacial de las represas de la región (Tabla 1). Considerando que se utilizaron variables vectoriales y ráster - estas últimas con distintas resoluciones espaciales y temporales-, fue necesario unificar la resolución de la información. Así se obtuvo un valor único para cada celda $\left(0.25^{\circ} \times 0.25^{\circ}\right)$ para cada variable. Debido a que los límites de las celdas de TRMM y los fijados por Oyarzabal et al. (2018) para la región de estudio no coinciden perfectamente, se decidió utilizar sólo las celdas TRMM cuya superficie estuviera comprendida al menos en un $70 \%$ dentro del Chaco Árido ( $\mathrm{n}=135$ celdas) con el objetivo de evitar el efecto borde. Para aquellas 


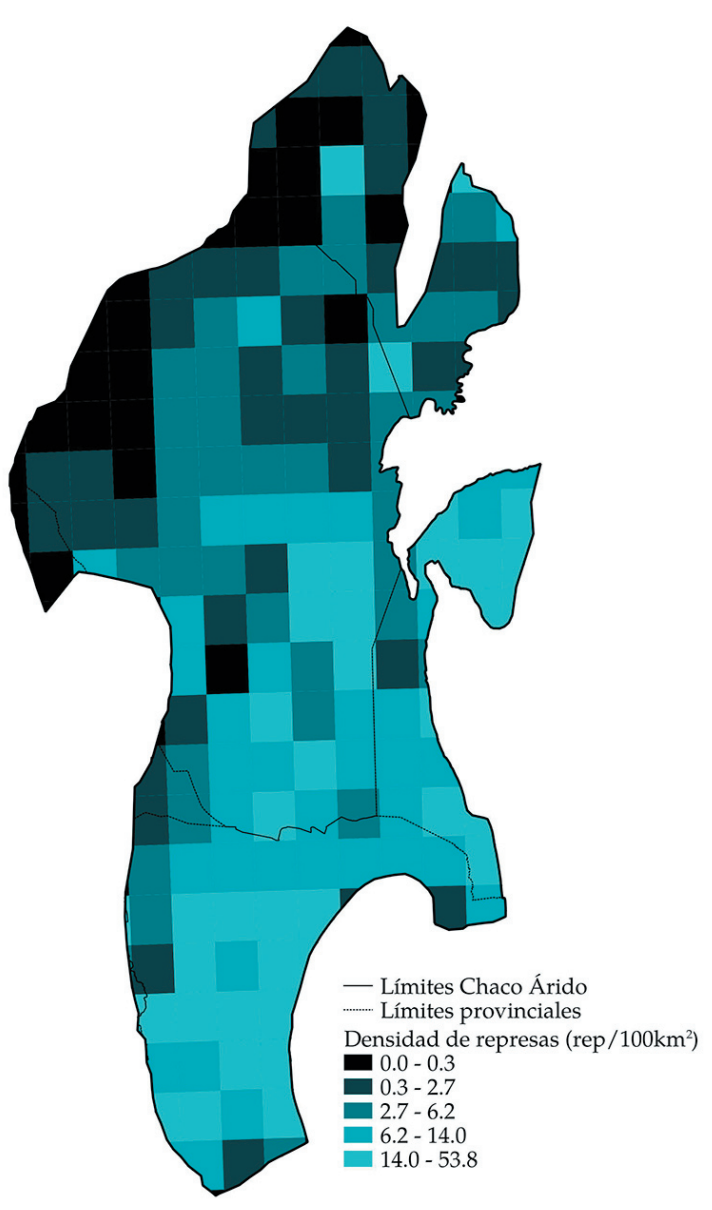

Figura 3. Mapa de densidad de represas (represas cada 100 $\mathrm{km}^{2}$ ) elaborado a partir de una grilla de $0.25^{\circ} \times 0.25^{\circ}$. Los cinco intervalos de densidad fueron construidos siguiendo la distribución de cuantiles.

Figure 3. Dams density map (dams every $100 \mathrm{~km}^{2}$ ) made from a $0.25^{\circ} \times 0.25^{\circ}$ grid. The five density intervals were constructed according to quantile distribution.

variables continuas en formato ráster cuyo pixel era menor al tamaño de las celdas se consideró la mediana espacial, según el caso, para integrar los valores de las variables a la grilla. Con una variable discreta como lo es la clasificación de coberturas y uso del suelo de MapBiomas, se calculó la proporción de bosque nativo y el número de parches de esta misma clase por celda. Las capas vectoriales de ríos y de caminos, por tratarse de líneas, se integraron a las celdas calculando la suma de las longitudes de cada vector y se lo relativizó a la superficie de cada celda, obteniendo la densidad de ríos $\left(\mathrm{km}\right.$ de ríos por $\mathrm{km}^{2}$ de superficie de celda) y densidad de caminos $\left(\mathrm{km}\right.$ de caminos por $\mathrm{km}^{2}$ de superficie de celda), respectivamente. Los datos ganaderos se integraron a la matriz a partir del cálculo del número de establecimientos por celda y la suma de las existencias ganaderas de los mismos. Esto se cuantificó en términos de carga animal dividiendo los equivalentes vaca totales, resultado de la suma de las cabezas de ganado de las distintas categorías, por la superficie de cada celda. Por otra parte, se calculó un índice de orientación productiva (novillos/vaca), uno reproductivo (terneros/vaca) y la proporción de pequeños rumiantes, calculada como el cociente entre los equivalentes vaca de pequeños rumiantes y los equivalentes vaca totales (carga animal).

Sobre las 17 variables presentadas en la Tabla 1 , determinadas en la misma escala espacial ( $\mathrm{n}=135$ celdas de $0.25^{\circ} \times 0.25^{\circ}$ cada una) se realizaron dos tipos de análisis. Por un lado, se llevaron a cabo correlaciones de Spearman entre cada una de las 16 variables biofísicas y la densidad de represas. De este modo, se buscó cuantificar la asociación individual de cada variable del entorno con la variable de interés de este estudio (densidad de represas). Se utilizó el coeficiente de correlación no paramétrico de Spearman debido a que la distribución de los datos no cumplía con el supuesto de normalidad (Wissler 1905). Se utilizó el paquete estadístico Prism 4 GraphPad Software y se asumieron niveles de significancia de 0.05 y 0.01 . Por otro lado, se realizó un análisis de componentes principales (PCA) de tipo exploratorio con el objetivo de identificar patrones generales del entorno y su relación con la densidad de las represas de la región. Para realizar el PCA, previamente se normalizaron los datos de cada variable dividiendo el valor de cada celda por la media de la variable. Los dos análisis antes mencionados (correlación de Spearman y PCA) se complementaron con la interpretación visual de distintas sub-áreas de la región y el análisis de existencias de represas cercanas a caminos y ríos (zonas buffer). Se discuten las razones por las cuales se encontraron grandes zonas sin represas a partir del análisis e interpretación visual de las imágenes. Mediante el análisis de buffers de caminos y cauces de ríos se determinó el grado de asociación de las represas y estos dos elementos del paisaje en aquellas celdas en donde sí se detectaron represas. En este caso, se determinaron 10 zonas buffer centradas en los caminos y cauces de ríos (e.g., $100 \mathrm{~m}, 200 \mathrm{~m}, 300 \mathrm{~m}$, etc.) y se contabilizaron las represas ubicadas dentro de esas zonas buffer. Es importante mencionar que tanto la interpretación visual como el análisis 
Tabla 1. Listado de las 17 variables integradas en la grilla de trabajo $\left(0.25^{\circ} \times 0.25^{\circ}\right)$ junto con una breve descripción y la fuente de los datos.

Table 1. List of the 17 variables integrated in the working grid $\left(0.25^{\circ} \times 0.25^{\circ}\right)$ together with a brief description and the source of the data.

\begin{tabular}{|c|c|c|}
\hline Variable & Descripción & Origen de datos \\
\hline Densidad de represas & Densidad de represas por celda (represas $/ 100 \mathrm{~km}^{2}$ ) & $\begin{array}{l}\text { Represas identificadas (puntos) } \\
\text { y grilla vectorial TRMM cortada } \\
\text { (polígonos) }\end{array}$ \\
\hline NDVI media anual & $\begin{array}{l}\text { NDVI medio para el período 2000-2019. Valores } \\
\text { promedio de los pixeles }\end{array}$ & $\begin{array}{l}\text { NDVI (MOD13Q1) 2000-2019. } \\
\text { Resolución espacial } 250 \mathrm{~m}\end{array}$ \\
\hline $\begin{array}{l}\mathrm{N}^{\circ} \text { de parches de bosque } \\
\text { nativo }\end{array}$ & $\begin{array}{l}\text { Densidad de parches de bosques nativo por celda } \\
\left(\text { parches } / \mathrm{km}^{2} \text { ) }\right.\end{array}$ & $\begin{array}{l}\text { MapBiomas } 2017 . \\
\text { Resolución espacial } 30 \mathrm{~m}\end{array}$ \\
\hline NDVI CV intra anual & $\begin{array}{l}\text { Estacionalidad. Coeficiente de variación del NDVI } \\
\text { entre meses para el período 2000-2019. Valores } \\
\text { promedios de los pixeles }\end{array}$ & $\begin{array}{l}\text { NDVI (MOD13Q1) 2000-2019. } \\
\text { Resolución espacial 250m }\end{array}$ \\
\hline $\begin{array}{l}\text { Proporción de bosque } \\
\text { nativo }\end{array}$ & $\begin{array}{l}\text { Superficie de bosque nativo (clase 2) en relación con } \\
\text { la superficie de cada celda (\%) }\end{array}$ & $\begin{array}{l}\text { MapBiomas 2017. Resolución } \\
\text { espacial } 30 \mathrm{~m}\end{array}$ \\
\hline PPT media anual & $\begin{array}{l}\text { Precipitación media anual para el período 2000-2019 } \\
\text { (mm/año) }\end{array}$ & $\begin{array}{l}\text { TRMM 3B43 mensual 2000-2019. } \\
\text { Resolución espacial } 0.25^{\circ}\end{array}$ \\
\hline Índice de aridez & $\begin{array}{l}\text { Índice de aridez promedio anual. Valores promedio } \\
\text { de los pixeles }\end{array}$ & $\begin{array}{l}\text { AI_ET0 v2. Resolución espacial } \\
1 \mathrm{~km}\end{array}$ \\
\hline PPT CV inter anual & $\begin{array}{l}\text { Coeficiente de variación interanual de las } \\
\text { precipitaciones para el período } 2000-2019\end{array}$ & $\begin{array}{l}\text { TRMM 3B43 mensual 2000-2019. } \\
\text { Resolución espacial } 0.25^{\circ}\end{array}$ \\
\hline Carga animal & $\begin{array}{l}\text { Carga animal total correspondiente a categorías } \\
\text { bovinas y pequeños rumiantes }\left(\mathrm{EV} / \mathrm{km}^{2}\right)\end{array}$ & $\begin{array}{l}\text { Relevamiento vacunación } \\
\text { SENASA } 2019 \text { (puntos) }\end{array}$ \\
\hline $\begin{array}{l}\text { Densidad de } \\
\text { establecimientos }\end{array}$ & $\begin{array}{l}\text { Número de establecimientos por celda relativo a la } \\
\text { superficie de cada celda (establecimientos } / \mathrm{km}^{2} \text { ) }\end{array}$ & $\begin{array}{l}\text { Relevamiento vacunación } \\
\text { SENASA } 2019 \text { (puntos) }\end{array}$ \\
\hline $\begin{array}{l}\text { Proporción pequeños } \\
\text { rumiantes }\end{array}$ & $\begin{array}{l}\text { Relación entre equivalentes vaca de pequeños } \\
\text { rumiantes y equivalentes vaca totales por celda (\%) }\end{array}$ & $\begin{array}{l}\text { Relevamiento vacunación } \\
\text { SENASA } 2019 \text { (puntos) }\end{array}$ \\
\hline Terneros/vaca & $\begin{array}{l}\text { Eficiencia reproductiva. Relación entre el número } \\
\text { de terneros/as y el número de vacas por celda }\end{array}$ & $\begin{array}{l}\text { Relevamiento vacunación } \\
\text { SENASA } 2019 \text { (puntos) }\end{array}$ \\
\hline Novillos/vacas & $\begin{array}{l}\text { Relación entre el número de novillos y el número de } \\
\text { vacas por celda }\end{array}$ & $\begin{array}{l}\text { Relevamiento vacunación } \\
\text { SENASA } 2019 \text { (puntos) }\end{array}$ \\
\hline Densidad de caminos & $\begin{array}{l}\text { Longitud de caminos por celda relativo a la } \\
\text { superficie de cada celda }\left(\mathrm{km} / \mathrm{km}^{2}\right)\end{array}$ & RedCaminos IGN (líneas) \\
\hline Pendiente & $\begin{array}{l}\text { Pendiente }(\%) \text {. Valores correspondientes a la } \\
\text { mediana de los pixeles }\end{array}$ & $\begin{array}{l}\text { DSM (ALOS-PALSAR). } \\
\text { Resolución espacial } 30 \mathrm{~m}\end{array}$ \\
\hline Altitud & $\begin{array}{l}\text { Altitud (m s. n. m.). Valores correspondientes a la } \\
\text { mediana de los pixeles }\end{array}$ & $\begin{array}{l}\text { DSM (ALOS-PALSAR). } \\
\text { Resolución espacial } 30 \mathrm{~m}\end{array}$ \\
\hline Densidad de ríos & $\begin{array}{l}\text { Longitud de cursos de agua (transitorios y } \\
\text { permanentes) por celda relativo a la superficie de } \\
\text { cada celda }\left(\mathrm{km} / \mathrm{km}^{2}\right)\end{array}$ & RedRios IGN (líneas) \\
\hline
\end{tabular}

de buffers, proveen información específica sobre algunas celdas o zonas que no pueden ser relevadas claramente por los análisis de Spearman y PCA.

\section{Resultados}

Se identificaron 7920 represas en la totalidad de la superficie del Chaco Árido, equivalentes a una densidad promedio de 8.1 represas cada $100 \mathrm{~km}^{2}$. La mayor parte de las represas se encontró en la provincia de San Luis (38.1\%), seguida por La Rioja (36.5\%) y Córdoba $(18.8 \%)$. Considerando el número de represas relativo a la superficie ocupada por el Chaco Árido en cada provincia, Córdoba fue la provincia que tuvo mayor densidad, seguida por San Luis (16 y 14 represas cada $100 \mathrm{~km}^{2}$, 
respectivamente). La Rioja, que ocupa el 50\% de la superficie del Chaco Árido, presentó menos de la mitad de la densidad de represas que las provincias antes mencionadas (Tabla $2)$. En todas las provincias se observaron celdas con baja o nula presencia de represas y otras con densidades muy superiores a la media regional. Sin embargo, en Córdoba y San Luis se destaca el dominio de celdas con densidades correspondientes al percentil 75 (más de 14 represas cada 100 km²) (Figura 3).
El análisis de componentes principales capturó en los dos primeros componentes (factores) el $47.02 \%$ de la varianza total del conjunto de las variables analizadas (Figura 4). El Factor 1 (32.25\% de la varianza total) se vincula con variables relacionadas al clima (e.g., precipitación, índice de aridez), a la productividad primaria (e.g., NDVI) y a la producción secundaria (e.g., carga animal, densidad de establecimientos y caminos). El Factor 2 explicó el 14.77\% de la varianza

Tabla 2. Superficie, cantidad de represas total y densidad de represas (represas $/ \mathrm{km}^{2} \mathrm{o}$ ha/represas) de las provincias incluidas en la región del Chaco Árido. Los valores se ordenan de mayor a menor según la superficie que ocupan en la región (segunda columna).

Table 2. Area, total number of dams and density of dams (dams $/ \mathrm{km}^{2}$ or ha/dams) of the provinces included in the Arid Chaco region. The values are ordered from the highest to the lowest according to the area they occupy in the region (second column).

\begin{tabular}{lcccc}
\hline Provincia & Superficie $(\mathrm{km})$ & Represas & Represas $/ 100 \mathrm{~km}^{2}$ & ha/represas \\
\hline La Rioja & 49186 & 2892 & 6 & 1701 \\
San Luis & 21296 & 3021 & 14 & 705 \\
Catamarca & 14976 & 481 & 3 & 3114 \\
Córdoba & 9336 & 1492 & 16 & 626 \\
San Juan & 2463 & 21 & 1 & 11727 \\
Mendoza & 137 & 13 & 9 & 1055 \\
\multicolumn{1}{c}{ Total general } & 97394 & 7920 & 8 & 1230 \\
\hline
\end{tabular}

a)

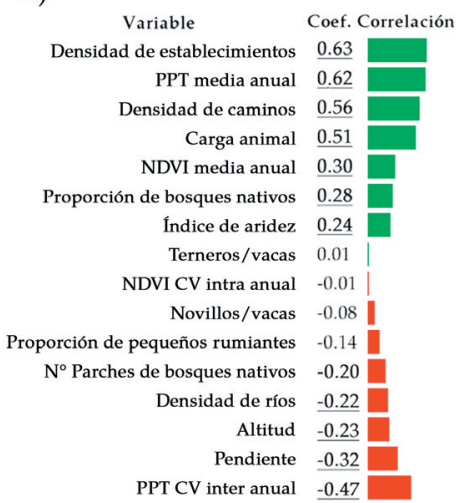

b)

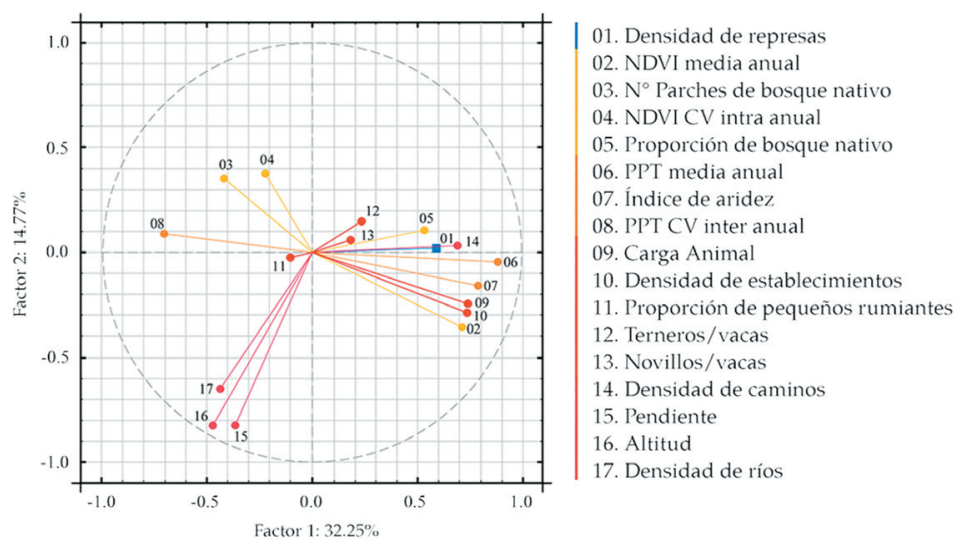

Figura 4. Asociaciones entre la densidad de represas y variables biofísicas del Chaco Árido. a) Coeficientes de correlación de Spearman entre la densidad de represas y 16 variables biofísicas. En negrita se destacan los coeficientes significativos con $\mathrm{P}<0.05$; en negrita y subrayado, los coeficientes con $\mathrm{P}<0.01$. El largo de las barras horizontales indica la magnitud de la correlación (en verde, los coeficientes positivos; en rojo, los negativos). b) Análisis de componentes principales que incorpora las 17 variables analizadas. El color de los vectores indica la naturaleza de las variables. Amarillo: producción primaria. Naranja: clima. Rojo: producción secundaria. Bordó: topografía, hidrografía. Azul: densidad de represas.

Figure 4. Associations between the dam density and biophysical variables in the Arid Chaco. a) Spearman's correlation coefficients between dam density and 16 biophysical variables. The coefficients with $\mathrm{P}<0.05$ are highlighted in bold, and the coefficients with $\mathrm{P}<0.01$ are highlighted in bold and underlined. The length of the horizontal bars indicates the magnitude of the correlation (positive coefficients in green and negative coefficients in red). $b$ ) Principal component analysis that incorporates the 17 variables analyzed. The color of the vectors indicates the type of the variable. Yellow: primary production-related variables. Orange: climate. Red: secondary production-related variables. Bordeaux: topography, hydrography. Blue: density of dams. 
total y estuvo relacionado con variables de tipo topográficas e hidrográficas (e.g., pendiente, altitud, densidad de cauces de ríos). La densidad de represas de la región estuvo principalmente explicada por el primer factor, mientras que la topografía tuvo escasa a nula incidencia. Los coeficientes de correlación mostraron que la densidad de represas fue mayor en celdas con mayor densidad de establecimientos ganaderos, caminos y carga animal $(r=0.63, r=0.56$ y $\mathrm{r}=0.51$, respectivamente; $\mathrm{P}<0.01$ en todos los casos), y en sitios con mayor precipitación media anual y menor variabilidad interanual ( $r=0.62$ y $r=-0.47$, respectivamente; $P<0.01$ para ambos casos).

Al analizar la distribución de las represas en la región, se identificaron patrones espaciales atribuibles a la combinación de ciertas variables ambientales: la topografía, la geomorfología, la cobertura vegetal y el uso del suelo (Figura 5). Por un lado, se observaron dos grandes extensiones, que en conjunto representan $3913 \mathrm{~km}^{2}$, constituidas por depósitos eólicos de arenas finas (dunas) en las que no se encontraron represas (Figura 5a). Por otro lado, en las cuatro áreas con afloramientos salinos, que suman un total de $1116 \mathrm{~km}^{2}$, tampoco se encontraron represas, posiblemente debido a la nula oferta forrajera y al exceso de sal en el agua cosechable (Figura $5 b)$. Finalmente, se identificaron áreas serranas y periserranas (que ocupan una superficie de $23388 \mathrm{~km}^{2}$ ) con baja a nula presencia de represas, posiblemente asociado a la escasez de forraje respecto del bosque de llanura circundante (Figura 5c). En este último caso, la distribución de las represas se observa asociada a las vías de escurrimiento natural (cauces y paleocauces) que ofrece el paisaje. Los tres patrones espaciales mencionados (dunas, salinas y sierras) ocupan $\sim 29 \%$ de la superficie del Chaco Árido. Es importante destacar que el valor promedio de 8.1 represas cada $100 \mathrm{~km}^{2}$ regional (1 represa cada 1230
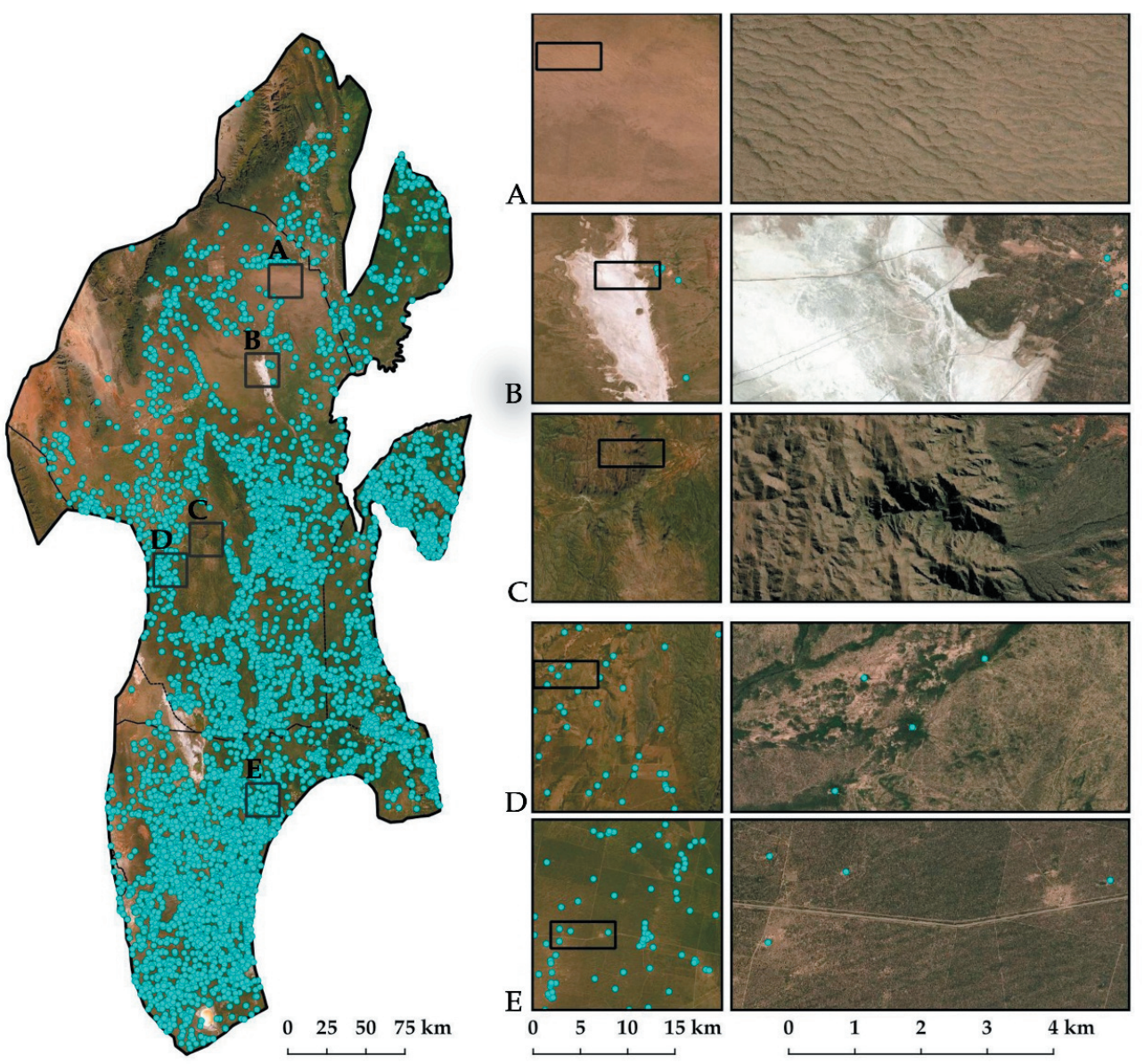

Figura 5. Patrones espaciales de distribución de las represas en distintas escalas. Los recuadros denominados A, B, C, D y E representan variaciones biofísicas dentro del Chaco Árido. Los puntos celestes se corresponden con las represas.

Figure 5. Spatial patterns of dams distribution at different scales. The boxes labeled A, B, C, D and E represent biophysical variations within the Arid Chaco. The light blue points correspond to the dams. 
ha) asciende a 11.5 represas por cada $100 \mathrm{~km}^{2}$ (1 represa cada 871 ha) si se descuentan estas tres superficies del total de la región. En el 71\% restante de la superficie, la distribución modal de las represas se presentó en las grandes planicies cubiertas por bosque nativo y estuvo mayormente influenciada por la distribución de las lluvias y la presencia de establecimientos ganaderos (Figura 5D). Las represas se ubican mayormente en torno a los caminos. Dichos caminos, muy frecuentemente, están asociados a áreas de suelo desnudo, baja cobertura vegetal y caminos de hacienda que convergen en la piósfera en torno a las represas (Figura 5e). En promedio para toda la región, el 20 y el $50 \%$ de las represas se encuentran a menos de 100 y 300 m de un camino, respectivamente.

\section{Discusión}

La cosecha de agua de lluvia en represas ha sido la clave para el desarrollo de la producción ganadera del Chaco Árido. En este estudio se cuantificaron y mapearon todas las represas de la región (Tabla 2, Figura 3). Asimismo, se caracterizó la distribución espacial de las represas y sus asociaciones con variables del ambiente (Figura 4 y 5). Hasta donde sabemos, no existe ningún trabajo que haya abordado esta problemática en la totalidad de la región. De nuestro análisis surge que la distribución de la densidad de las represas no es homogénea a lo largo y ancho de la región (Figura 3), por lo cual, se acepta la hipótesis 1 planteada al inicio de este trabajo. El rango de densidades de represas encontrado fue muy amplio, lo cual siguiere, además, que existe una gran heterogeneidad del paisaje dentro de la región. Por otra parte, si bien la precipitación resultó ser una de las variables que más se asoció a la distribución espacial de las represas, existieron otros atributos biofísicos a considerar; por ejemplo, la carga animal y la densidad de establecimientos y de caminos (Figura 4), así como variables relacionadas con factores edáficos (Figura 5). Sobre la base de estos hallazgos, aceptamos parcialmente la hipótesis 2 propuesta. A continuación se proporcionan elementos adicionales (e.g., argumentos extraídos de la literatura y observaciones de campo) para dar un marco conceptual al contraste de nuestras hipótesis.

Si bien la precipitación media anual es la variable que mejor se asoció a la distribución de las represas a escala regional $(\mathrm{r}=0.62)$, existen otros factores que escapan a la relación lineal entre lluvias y densidad de represas (Figura 6b). Una forma de ver esto es, por ejemplo, analizando el número de represas por establecimiento ganadero en función del gradiente de lluvia media anual (Figura 6a). Como se puede observar, la cantidad de represas es mayor en el rango intermedio de precipitación (entre 400 y 600 $\mathrm{mm} / \mathrm{anno}$ ) y decrece hacia los límites árido y subhúmedo. La menor cantidad de represas por establecimiento en zonas áridas se puede explicar por el factor económico, debido a los bajos márgenes de producción y rentabilidades de esos campos (Quiroga et al. 2009b). Por su parte, la menor cantidad de represas por establecimiento en zonas subhúmedas puede ser explicada por 1) la mayor eficiencia en la cosecha de agua de las represas como resultado de una mayor disponibilidad del agua de lluvia, 2) el acceso a otras fuentes de suministro de agua para bebida (acueductos en las cercanías de las sierras), o 3) la oferta hídrica de esta zona que permite combinar la producción ganadera extensiva con cultivos agrícolas de secano, los cuales no requieren de la cosecha de agua (Karlin et al. 2013). Asimismo, es esencial destacar que el factor edáfico, sobre todo la textura del suelo, puede limitar la construcción de represas, en especial en los ambientes medanosos (Peña Zubiate et al. 1998; Kirby et al. 2001; Coirini et al. 2010). Debido a que no contamos con datos edáficos con un nivel de detalle adecuado para incorporar al análisis regional realizado en las 135 celdas, dejamos planteado este interrogante para futuras investigaciones.

El hecho de que las represas se concentren en torno a los caminos y en menor medida a los cursos de agua (fundamentalmente antiguos y transitorios), sugiere que los caminos podrían cumplir una función clave en el llenado de las represas. Si bien los caminos son construidos para poder ingresar la maquinaria al campo para realizar la construcción y el mantenimiento de las represas, una vez construidos, los caminos pueden jugar un papel en el aporte de escurrimiento superficial. Esto cobra especial relevancia en sistemas con altas tasas de infiltración del suelo y vegetación perenne, lo cual previene el escurrimiento en gran parte de la superficie (Magliano et al. 2017; Karlin et al. 2019; Nosetto et al. 2020). Muchos autores encontraron que el escurrimiento superficial neto en planicies con índices de aridez similares al Chaco Árido difícilmente supera el 5\% de la precipitación anual (Bergkamp 1998; Newman et al. 2006; Rodríguez et al. 2020; Vivoni et al. 2021). En 

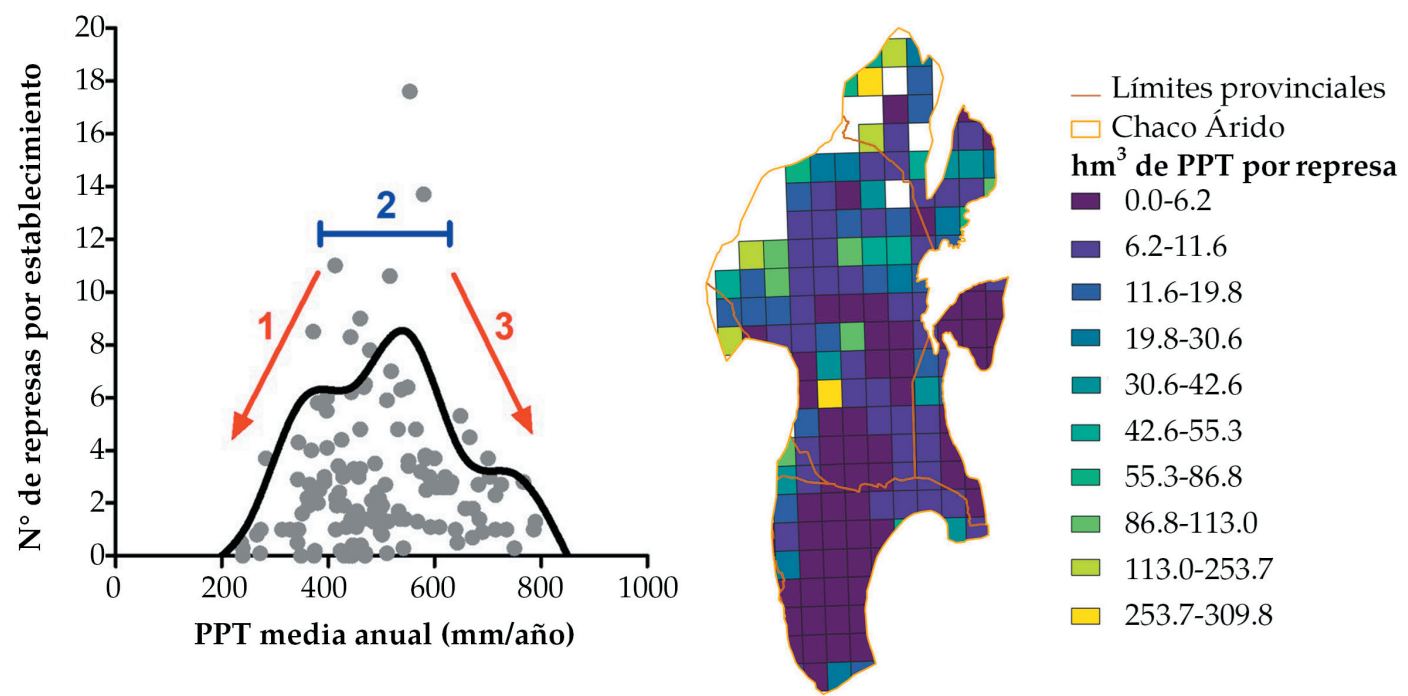

Figura 6. Distribución de las represas en función de la precipitación media anual. a) Número de represas por establecimiento, calculado como el cociente entre la cantidad de represas y la cantidad de establecimientos por celda, a lo largo de un gradiente de precipitación media anual creciente. Cada marcador representa una celda de $0.25^{\circ} \times 0.25^{\circ}$ ( $\mathrm{n}=135$ celdas). La línea negra llena muestra el percentil 90 de los datos. Las flechas rojas descendentes indican los rangos de precipitación media anual en los cuales el número de represas por establecimiento disminuye. La línea azul indica el rango óptimo de precipitación media anual en el que se maximiza el número de represas por establecimiento. b) Volumen de precipitación media anual por cada represa, elaborado en base a la capa de precipitación media anual (TRMM), calculando el volumen de lluvia media anual $\left(\mathrm{hm}^{3}\right)$ para cada celda y su relación con la densidad de represas.

Figure 6. Distribution of dams as a function of mean annual rainfall. a) Number of dams per establishment calculated as the ratio between the number of dams and the number of establishments per cell, along an increasing mean annual precipitation gradient. Each marker represents a $0.25^{\circ} \times 0.25^{\circ}$ cell ( $\mathrm{n}=135$ cells). The solid black line shows the 90 th percentile of the data. The descending red arrows indicate the ranges of mean annual precipitation in which the number of dams per establishment decreases. The blue line indicates the optimal range of mean annual precipitation where the number of dams per establishment is maximized. b) Volume of mean annual rainfall for each dam estimated based on the mean annual rainfall layer (TRMM) and calculating the mean annual rainfall volume $\left(\mathrm{hm}^{3}\right)$ for each cell and its relationship with the density of dams.

estos casos, cualquier labor realizada en un campo, como puede ser un camino, una picada o sectores puntuales expuestos a pastoreo intenso, pueden alterar mucho la circulación superficial del agua. Este tipo de situaciones son las que pueden favorecer los procesos de cosecha de agua por parte de las represas, a pesar de no haber sido específicamente diseñados para ello.

Un aspecto interesante sobre la relación entre la densidad de represas y la oferta hídrica del sistema es el hecho de que la precipitación media anual explique más variabilidad que el índice de aridez. En general, el índice de aridez suele ser una variable más integral que la lluvia porque comprende a la misma y a la demanda atmosférica. Si bien los modelos de crecimiento y distribución de la vegetación de zonas áridas suelen utilizar al índice de aridez como variable explicativa, en el caso de la cosecha de agua existe una gran diferencia que radica en las características de los eventos de lluvia. Los años que presentan mayor precipitación media anual también presentan mayor proporción de eventos grandes (percentil 10 de tamaño) (Magliano et al. 2015a). Es probable que el llenado de las represas se ajuste mejor a disponer de 4 o 5 eventos grandes de lluvia que al balance hídrico diario (reflejado de mejor manera por el índice de aridez). Para entender mejor el proceso de cosecha de agua de las represas resulta necesario realizar estudios de campo minuciosos y precisos que logren determinar el efecto de las características de los eventos de lluvia (e.g., tamaño, intensidad, duración, intervalos entre eventos) y la generación de escurrimiento. Este trabajo pone en evidencia la importancia de destinar esfuerzo a entender el funcionamiento ecohidrológico de estos sistemas debido a que no se trata de casos aislados e infrecuentes, sino que representan un recurso estratégico para la totalidad de la región y puede afectar a la estructura de las poblaciones naturales y la estructura y dinámica de comunidades en los ecosistemas. En este sentido, el relevamiento de represas 
abre la posibilidad a seguir analizando el impacto que tienen estos cuerpos de agua a escala regional.

\section{Conclusiones}

Las represas chaqueñas han sido fundamentales en el asentamiento de comunidades y la producción ganadera del Chaco Árido. En este trabajo, encontramos que el NDWI (elaborado en base a imágenes Sentinel 2A) permitió detectar la gran mayoría de las represas activas observadas. En total, se identificaron 7920 represas, 1o cual representa 8.1 represas cada $100 \mathrm{~km}^{2}$, observándose un gradiente creciente en el sentido noroeste a sureste. La densidad de represas fue mayor en ambientes con mayor densidad de establecimientos ganaderos, caminos y carga animal, y en sitios con mayor precipitación media anual y menor variabilidad interanual. Sin embargo, en todas estas situaciones descriptas se identificaron áreas con baja densidad de represas, lo cual se debe a la incidencia de otros factores como la presencia de dunas, salinas o sierras. Este trabajo representa la primera aproximación regional al estudio de las represas en el Chaco Árido. Saber la cantidad de represas presentes permite dimensionar la magnitud de la cosecha de agua de lluvia y su almacenamiento en toda la región. Esto se traduce en conocer las características de quizás el recurso más escaso y estratégico de la región, y contribuye a entender de manera integral el funcionamiento ecohidrológico y socioeconómico del Chaco Árido.

Agradecimientos. Se agradece a Lisandro Blanco, Guillermo Ojeda y Germán Baldi por sus sugerencias en los primeros estadios de este manuscrito. También se agradece la colaboración de Diego Pereyra y Ernesto Pelliza por el acceso a datos de campo de los llanos riojanos, y de Juan Whitworth Hulse por las sugerencias sobre el análisis de los datos. Este trabajo fue realizado en las instalaciones del "Grupo de Estudios Ambientales" (IMASL-CONICET-UNSL) y solventado por los subsidios PICT 2016-4136 y PIP 112-201501-00609.

\section{REFERENCIAS}

Aguilera, M. O., D. F. Steinaker, and M. R. Demaria. 2003. Runoff and soil loss in undisturbed and roller-seeded shrublands of semiarid Argentina. Journal of Range Management 56:227-233. https://doi.org/10.2307/4003811.

Anriquez, A., A. Albanesi, C. Kunst, R. Ledesma, C. López, A. Rodríguez Torresi, and J. Godoy. 2005. Rolado de fachinales y calidad de suelos en el Chaco occidental, Argentina. Ciencia del Suelo 23:145-157.

Asner, G. P., A. J. Elmore, L. P. Olander, R. E. Martin, and A. T. Harris. 2004. Grazing systems, ecosystem responses, and global change. Annu Rev Environ Resour 29:261-299. https://doi.org/10.1146/annurev.energy.29.062403.102142.

Baldi, G., S. R. Verón, and E. G. Jobbágy. 2013. The imprint of humans on landscape patterns and vegetation functioning in the dry subtropics. Global Change Biology 19:441-458. https://doi.org/10.1111/gcb.12060.

Basán Nickisch, M. 2010. Manejo de recursos hídricos para áreas de secano. Instituto Nacional de Tecnología Agropecuaria.

Basán Nickisch, M. 2013. Experiencias de captación de agua de lluvia para la recarga artificial de acuíferos someros en el chaco argentino. En Aprovechamiento sustentable de los recursos hídricos para el sistema agropecuario en condiciones semiáridas.

Basant, S., B. P. Wilcox, P. M. Leite, and C. L. Morgan. 2020. When savannas recover from overgrazing, ecohydrological connectivity collapses. Environmental Research Letters 15:054001. https://doi.org/10.1088/1748-9326/ab71a1.

Bergkamp, G. 1998. A hierarchical view of the interactions of runoff and infiltration with vegetation and microtopography in semiarid shrublands. Catena 33:201-220. https://doi.org/10.1016/S0341-8162(98)00092-7.

Bestelmeyer, B. T., G. S. Okin, M. C. Duniway, S. R. Archer, N. F. Sayre, J. C. Williamson, and J. E. Herrick. 2015. Desertification, land use, and the transformation of global drylands. Frontiers in Ecology and the Environment 13: 28-36. https://doi.org/10.1890/140162.

Biazin, B., G. Sterk, M. Temesgen, A. Abdulkedir, and L. Stroosnijder. 2012. Rainwater harvesting and management in rainfed agricultural systems in sub-Saharan Africa-a review. Physics and Chemistry of the Earth, Parts A/B/C 47: 139-151. https://doi.org/10.1016/j.pce.2011.08.015

Blanco, L., M. Aguilera, J. Paruelo, and F. Biurrun. 2008. Grazing effect on NDVI across an aridity gradient in Argentina. Journal of Arid Environments 72:764-776. https://doi.org/10.1016/j.jaridenv.2007.10.003.

Blanco, L. J., C. A. Ferrando, and F. N. Biurrun. 2009. Remote sensing of spatial and temporal vegetation patterns in two grazing systems. Rangeland Ecology and Management 62:445-451. https://doi.org/10.2111/08-213.1.

Blanco, L. J., C. A. Ferrando, F. N. Biurrun, E. L. Orionte, P. Namur, D. J. Recalde, and G. D. Berone. 2005. Vegetation responses to roller chopping and buffelgrass seeding in Argentina. Rangeland Ecology and Management 58:219-224. https://doi.org/10.2111/1551-5028(2005)58[219:VRTRCA]2.0.CO;2.

Bogino, S., and M. Bravo. 2014. Impacto del rolado sobre la biodiversidad de especies leñosas y la biomasa individual de jarilla (Larrea divaricata) en el Chaco Árido Argentino. Quebracho-Revista de Ciencias Forestales 22.

Chillo, V., R. A. Ojeda, M. Anand, and J. F. Reynolds. 2015. A novel approach to assess livestock management effects 
on biodiversity of drylands. Ecological Indicators 50:69-78. https://doi.org/10.1016/j.ecolind.2014.10.009.

Coirini, R. O., M. S. Karlin, and G. J. Reati. 2010. Manejo sustentable del ecosistema Salinas Grandes, Chaco árido. Marcos Sebastián Karlin.

Contreras, S., C. S. Santoni, and E. G. Jobbágy. 2013. Abrupt watercourse formation in a semiarid sedimentary landscape of central Argentina: The roles of forest clearing, rainfall variability and seismic activity. Ecohydrology 6:794-805. https://doi.org/10.1002/eco.1302.

D'Odorico, P., A. Bhattachan, K. F. Davis, S. Ravi, and C. W. Runyan. 2013. Global desertification: drivers and feedbacks. Advances in Water Resources 51:326-344. https://doi.org/10.1016/j.advwatres.2012.01.013.

Denison, J. A., and L. Wotshela. 2012. An overview of indigenous, indigenised and contemporary water harvesting and conservation practices in south Africa. Irrigation and Drainage 61:7-23. https://doi.org/10.1002/ird.1689.

Descroix, L., G. Mahé, T. Lebel, G. Favreau, S. Galle, E. Gautier, J. Olivry, J. Albergel, O. Amogu, and B. Cappelaere. 2009. Spatio-temporal variability of hydrological regimes around the boundaries between Sahelian and Sudanian areas of West Africa: A synthesis. Journal of Hydrology 375:90-102. https://doi.org/10.1016/j.jhydrol.2008.12.012.

Erb, K.-H., T. Fetzel, T. Kastner, C. Kroisleitner, C. Lauk, A. Mayer, and M. Niedertscheider. 2016. Livestock grazing, the neglected land use. Pp. 295-313 en Social Ecology. Springer. https://doi.org/10.1007/978-3-319-33326-7_13.

Evenari, M., L. Shanan, and N. Tadmor. 1971. The Negev. The challenge of a desert. Second edition. Harvard University Press.

Feng, S., and Q. Fu. 2013. Expansion of global drylands under a warming climate. Atmos Chem Phys 13:081-010. https: //doi.org/10.5194/acp-13-10081-2013.

Fernández Duque, J. 1988. Tajamares y pozones: una solución siempre vigente. INTA Trelew, Argentina.

Fernández, P., M. Baumann, G. Baldi, N. R. Banegas, S. Bravo, N. I. Gasparri, M. Lucherini, M. S. Marinaro Fuentes, A. S. Nanni, and J. A. Nasca. 2019. Grasslands and Open Savannas of the Dry Chaco. https://doi.org/10.1016/B9780-12-409548-9.12094-9.

Fernández, P. D., T. Kuemmerle, M. Baumann, H. R. Grau, J. A. Nasca, A. Radrizzani, and N. I. Gasparri. 2020. Understanding the distribution of cattle production systems in the South American Chaco. Journal of Land Use Science 15:52-68. https://doi.org/10.1080/1747423X.2020.1720843.

García, A. G., C. M. Di Bella, J. Houspanossian, P. N. Magliano, E. G. Jobbágy, G. Posse, R. J. Fernández, and M. D. Nosetto. 2017. Patterns and controls of carbon dioxide and water vapor fluxes in a dry forest of central Argentina. Agricultural and Forest Meteorology 247:520-532. https://doi.org/10.1016/j.agrformet.2017.08.015.

Giménez, R., J. L. Mercau, F. E. Bert, S. Kuppel, G. Baldi, J. Houspanossian, P. N. Magliano, and E. G. Jobbágy. 2020. Hydrological and productive impacts of recent land-use and land-cover changes in the semiarid Chaco: Understanding novel water excess in water scarce farmlands. Ecohydrology 13:e2243. https://doi.org/10.1002/eco.2243.

Godfray, H. C. J., J. R. Beddington, I. R. Crute, L. Haddad, D. Lawrence, J. F. Muir, J. Pretty, S. Robinson, S. M. Thomas, and C. Toulmin. 2010. Food security: the challenge of feeding 9 billion people. Science 327:812-818. https://doi.org/ $10.1126 /$ science. 1185383 .

Graetz, R., and J. Ludwig. 1976. A method for the analysis of piosphere data applicable to range assessment. The Rangeland Journal 1:126-136. https://doi.org/10.1071/RJ9780126.

Greslebin, H. 1931. Las represas de la región occidental de la travesía puntana (provincia de San Luis). Sección Geografía Humana de la Primera Reunión Nacional de Geografía.

Heshmatti, G., J. Facelli, and J. Conran. 2002. The piosphere revisited: plant species patterns close to waterpoints in small, fenced paddocks in chenopod shrublands of South Australia. Journal of Arid Environments 51:547-560. https: //doi.org/10.1016/S0140-1963(02)90969-9.

Hoff, H., M. Falkenmark, D. Gerten, L. Gordon, L. Karlberg, and J. Rockström. 2010. Greening the global water system. Journal of Hydrology 384:177-186. https://doi.org/10.1016/j.jhydrol.2009.06.026.

Huang, J., H. Yu, X. Guan, G. Wang, and R. Guo. 2016. Accelerated dryland expansion under climate change. Nature Climate Change 6:166-171. https://doi.org/10.1038/nclimate2837.

IPCC. 2014. Climate change 2013: the physical science basis: Working Group I contribution to the Fifth assessment report of the Intergovernmental Panel on Climate Change. Cambridge University Press.

Iriondo, M. 1993. Geomorphology and late quaternary of the Chaco (South America). Geomorphology 7:289-303. https: //doi.org/10.1016/0169-555X(93)90059-B.

Jackson, R. B., S. R. Carpenter, C. N. Dahm, D. M. McKnight, R. J. Naiman, S. L. Postel, and S. W. Running. 2001. Water in a changing world. Ecological Applications 11:1027-1045. https://doi.org/10.1890/1051-0761(2001)011[1027: WIACW]2.0.CO;2.

Kahinda, J. M., and A. Taigbenu. 2011. Rainwater harvesting in South Africa: Challenges and opportunities. Physics and Chemistry of the Earth, Parts A/B/C 36:968-976. https://doi.org/10.1016/j.pce.2011.08.011.

Kaptué, A. T., N. P. Hanan, and L. Prihodko. 2013. Characterization of the spatial and temporal variability of surface water in the Soudan-Sahel region of Africa. Journal of Geophysical Research: Biogeosciences 118:1472-1483. https: //doi.org/10.1002/jgrg.20121.

Karlin, M., S. Bernasconi, A. Cora, S. Sánchez, S. Arnulphi, and R. Accietto. 2019. Changes in soil use: infiltration capacity in the center of Córdoba (Argentina). Ciencia del Suelo 37:196-208. https://doi.org/10.31047/1668.298x.v37.n1.28068.

Karlin, M. S., U. O. Karlin, R. O. Coirini, G. J. Reati, and R. M. Zapata. 2013. El Chaco Árido. Universidad Nacional de Córdoba, Córdoba, Argentina. Pp. 420. https://doi.org/10.1155/2013/945190.

Kirby, J., R. Kingham, and M. Cortes. 2001. Texture, density and hydraulic conductivity of some soils in San Luis 
province, Argentina. Ciencia del Suelo 19:20-29.

Kuemmerle, T., K. Erb, P. Meyfroidt, D. Müller, P. H. Verburg, S. Estel, H. Haberl, P. Hostert, M. R. Jepsen, and T. Kastner. 2013. Challenges and opportunities in mapping land use intensity globally. Current Opinion in Environmental Sustainability 5:484-493. https://doi.org/10.1016/j.cosust.2013.06.002.

Lal, R. 2004. Carbon sequestration in dryland ecosystems. Environmental Management 33:528-544. https://doi.org/ 10.1007/s00267-003-9110-9.

Lange, R. T. 1969. The piosphere: sheep track and dung patterns. Rangeland Ecology and Management/Journal of Range Management Archives 22:396-400. https://doi.org/10.2307/3895849.

Lavee, H., J. Poesen, and A. Yair. 1997. Evidence of high efficiency water-harvesting by ancient farmers in the Negev Desert, Israel. Journal of Arid Environments 35:341-348. https://doi.org/10.1006/jare.1996.0170.

Lundgren, E. J., D. Ramp, J. C. Stromberg, J. Wu, N. C. Nieto, M. Sluk, K. T. Moeller, and A. D. Wallach. 2021. Equids engineer desert water availability. Science 372:491-495. https://doi.org/10.1126/science.abd6775.

Llano, M. P. 2018. Spatial distribution of the daily rainfall concentration index in Argentina: comparison with other countries. Theoretical and Applied Climatology 133:997-1007. https://doi.org/10.1007/s00704-017-2236-0.

Macchi, L., and H. R. Grau. 2012. Piospheres in the dry Chaco. Contrasting effects of livestock puestos on forest vegetation and bird communities. Journal of Arid Environments 87:176-187. https://doi.org/10.1016/j.jaridenv.2012.06.003.

Magliano, P. N., R. J. Fernández, E. L. Florio, F. Murray, and E. G. Jobbágy. 2017. Soil physical changes after conversion of woodlands to pastures in Dry Chaco rangelands (Argentina). Rangeland Ecology and Management 70:225-229. https://doi.org/10.1016/j.rama.2016.08.003.

Magliano, P. N., R. J. Fernández, R. Giménez, V. A. Marchesini, R. A. Páez, and E. G. Jobbágy. 2016. Cambios en la partición de flujos de agua en el Chaco Árido al reemplazar bosques por pasturas. Ecología Austral 26:95-106. https: //doi.org/10.25260/EA.16.26.2.0.148.

Magliano, P. N., R. J. Fernández, J. L. Mercau, and E. G. Jobbágy. 2015a. Precipitation event distribution in central Argentina: Spatial and temporal patterns. Ecohydrology 8:94-104. https://doi.org/10.1002/eco.1491.

Magliano, P. N., D. Mindham, W. Tych, F. Murray, M. D. Nosetto, E. G. Jobbágy, M. J. Niborski, M. C. Rufino, and N. A. Chappell. 2019a. Hydrological functioning of cattle ranching impoundments in the Dry Chaco rangelands of Argentina. Hydrology Research 50:1596-1608. https://doi.org/10.2166/nh.2019.149.

Magliano, P. N., F. Murray, G. Baldi, S. Aurand, R. A. Páez, W. Harder, and E. G. Jobbágy. 2015b. Rainwater harvesting in Dry Chaco: Regional distribution and local water balance. Journal of Arid Environments 123:93-102. https://doi.org/ 10.1016/j.jaridenv.2015.03.012.

Magliano, P. N., J. I. Whitworth-Hulse, E. L. Florio, E. C. Aguirre, and L. J. Blanco. 2019b. Interception loss, throughfall and stemflow by Larrea divaricata: The role of rainfall characteristics and plant morphological attributes. Ecological Research 34:753-764. https://doi.org/10.1111/1440-1703.12036.

Manthey, M., and J. Peper. 2010. Estimation of grazing intensity along grazing gradients-the bias of nonlinearity. Journal of Arid Environments 74:1351-1354. https://doi.org/10.1016/j.jaridenv.2010.05.007.

Marchesini, V. A., R. J. Fernández, J. F. Reynolds, J. A. Sobrino, and C. M. Di Bella. 2015. Changes in evapotranspiration and phenology as consequences of shrub removal in dry forests of central Argentina. Ecohydrology 8:1304-1311. https://doi.org/10.1002/eco.1583.

Mbilinyi, B. P., S. D. Tumbo, H. F. Mahoo, E. M. Senkondo, and N. Hatibu. 2005. Indigenous knowledge as decision support tool in rainwater harvesting. Physics and Chemistry of the Earth 30:792-798. https://doi.org/10.1016/ j.pce.2005.08.022.

McFeeters, S. K. 1996. The use of the Normalized Difference Water Index (NDWI) in the delineation of open water features. International Journal of Remote Sensing 17:1425-1432. https://doi.org/10.1080/01431169608948714.

McNaughton, S. J., M. Oesterheld, D. A. Frank, and K. Williams. 1989. Ecosystem-level patterns of primary productivity and herbivory in terrestrial habitats. Nature 341:142-144. https://doi.org/10.1038/341142a0.

Moreno-de las Heras, M., P. M. Saco, G. R. Willgoose, and D. J. Tongway. 2011. Assessing landscape structure and pattern fragmentation in semiarid ecosystems using patch-size distributions. Ecological Applications 21:2793-2805. https://doi.org/10.1890/10-2113.1.

Moretti, L. M., H. J. M. Morrás, F. X. Pereyra, and G. A. Schulz. 2019. Soils of the Chaco Region in G. Rubio, R. S. Lavado and F. X. Pereyra (eds.). The Soils of Argentina. $1^{\text {st }}$ edition. Springer. Cham, Switzerland. https://doi.org/10.1007/9783-319-76853-3_10.

Newman, B. D., B. P. Wilcox, S. R. Archer, D. D. Breshears, C. N. Dahm, C. J. Duffy, N. G. McDowell, F. M. Phillips, B. R. Scanlon, and E. R. Vivoni. 2006. Ecohydrology of water-limited environments: A scientific vision. Water Resources Research 42:1-15. https://doi.org/10.1029/2005WR004141.

Ngigi, S. N. 2003. What is the limit of up-scaling rainwater harvesting in a river basin? Physics and Chemistry of the Earth 28:943-956. https://doi.org/10.1016/j.pce.2003.08.015.

Nosetto, M. D., E. Luna Toledo, P. N. Magliano, P. Figuerola, L. J. Blanco, and E. G. Jobbágy. 2020. Contrasting CO2 and water vapour fluxes in dry forest and pasture sites of central Argentina. Ecohydrology 13:e2244. https://doi.org/ 10.1002/eco.2244.

Oesterheld, M., O. Sala, and S. McNaughton. 1992. Effect of animal husbandry on herbivore-carrying capacity at a regional scale. Nature 356:234-236. https://doi.org/10.1038/356234a0.

Oweis, T., and A. Hachum. 2009a. Optimizing supplemental irrigation: Tradeoffs between profitability and sustainability. Agricultural Water Management 96:511-516. https://doi.org/10.1016/j.agwat.2008.09.029. 
Oweis, T., and A. Hachum. 2009b. Water harvesting for improved rainfed agriculture in the dry environments. Pp. 164-182 in S. P. Wani ( ed.). Rainfed Agriculture: Unlocking the Potential. CAB International. London, UK. https: //doi.org/10.1079/9781845933890.0164.

Oyarzabal, M., J. Clavijo, L. Oakley, F. Biganzoli, P. Tognetti, I. Barberis, H. M. Maturo, R. Aragón, P. I. Campanello, and D. Prado. 2018. Unidades de vegetación de la Argentina. Ecología Austral 28:040-063. https://doi.org/10.25260/ EA.18.28.1.0.399.

Paruelo, J. M., H. E. Epstein, W. K. Lauenroth, and I. C. Burke. 1997. ANPP estimates from NDVI for the central grassland region of the United States. Ecology 78:953-958. https://doi.org/10.1890/0012-9658(1997)078[0953:AEFNFT]2.0.CO;2.

Pellegrini, P., and R. J. Fernández. 2018. Crop intensification, land use, and on-farm energy-use efficiency during the worldwide spread of the green revolution. Proceedings of the National Academy of Sciences 115:2335-2340. https: //doi.org/10.1073/pnas.1717072115.

Pennington, T. R., D. E. Prado, and C. A. Pendry. 2000. Neotropical seasonally dry forests and Quaternary vegetation changes. Journal of Biogeography 27:261-273. https://doi.org/10.1046/j.1365-2699.2000.00397.x.

Peña Zubiate, C. A., D. L. Anderson, M. A. Demmi, J. L. Saenz, and A. D’Hiriart. 1998. Carta de suelos y vegetación de la provincia de San Luis. Instituto Nacional de Tecnología Agropecuaria, San Luis, Argentina.

Prăvălie, R. 2016. Drylands extent and environmental issues. A global approach. Earth-Science Reviews 161:259-278. https://doi.org/10.1016/j.earscirev.2016.08.003.

Quiroga, E., L. Blanco, and E. Orionte. 2009a. Evaluación de estrategias de rehabilitación de pastizales áridos. Ecología Austral 19:107-117.

Quiroga, R. E., L. J. Blanco, and C. A. Ferrando. 2009b. A case study evaluating economic implications of two grazing strategies for cattle ranches in northwest Argentina. Rangeland Ecology and Management 62:435-444. https://doi.org/ 10.2111/08-044.1.

Rockström, J., and M. Falkenmark. 2015. Agriculture: Increase water harvesting in Africa. Nature News 519:283. https: //doi.org/10.1038/519283a.

Rodriguez, P., R. Giménez, M. D. Nosetto, E. G. Jobbágy, and P. N. Magliano. 2020. Changes in water fluxes partition related to the replacement of native dry forests by crops in the Dry Chaco. Journal of Arid Environments 183:104281. https://doi.org/10.1016/j.jaridenv.2020.104281.

Rueda, C. V., G. Baldi, S. R. Verón, and E. G. Jobbágy. 2013. Apropiación humana de la producción primaria en el Chaco Seco. Ecología Austral 23:44-54. https://doi.org/10.25260/EA.13.23.1.0.1191.

Saco, P. M., J. F. Rodríguez, M. Moreno-de las Heras, S. Keesstra, S. Azadi, S. Sandi, J. Baartman, J. Rodrigo-Comino, and M. J. Rossi. 2020. Using hydrological connectivity to detect transitions and degradation thresholds: Applications to dryland systems. Catena 186:104354. https://doi.org/10.1016/j.catena.2019.104354.

Samways, M. J., C. Deacon, G. J. Kietzka, J. S. Pryke, C. Vorster, and J. P. Simaika. 2020. Value of artificial ponds for aquatic insects in drought-prone southern Africa: a review. Biodiversity and Conservation 29:3131-3150. https: //doi.org/10.1007/s10531-020-02020-7.

Scanlon, B. R., R. C. Reedy, D. A. Stonestrom, D. E. Prudic, and K. F. Dennehy. 2005. Impact of land use and land cover change on ground water recharge and quality in the southwestern US. Global Change Biology 11(10):1577-1593. https: //doi.org/10.1111/j.1365-2486.2005.01026.x.

Syvitski, J., C. N. Waters, J. Day, J. D. Milliman, C. Summerhayes, W. Steffen, J. Zalasiewicz, A. Cearreta, A. Gałuszka, and I. Hajdas. 2020. Extraordinary human energy consumption and resultant geological impacts beginning around 1950 CE initiated the proposed Anthropocene Epoch. Commun Earth Environ 1:32. https://doi.org/10.1038/s43247020-00029-y.

Thornton, P. K. 2010. Livestock production: recent trends, future prospects. Philosophical Transactions of the Royal Society B: Biological Sciences 365(1554):2853-2867. https://doi.org/10.1098/rstb.2010.0134.

Todd, S. W. 2006. Gradients in vegetation cover, structure and species richness of Nama-Karoo shrublands in relation to distance from livestock watering points. Journal of Applied Ecology 43:293-304. https://doi.org/10.1111/j.13652664.2006.01154.x.

Tripaldi, A., M. A. Zárate, S. L. Forman, T. Badger, M. E. Doyle, and P. Ciccioli. 2013. Geological evidence for a drought episode in the western Pampas (Argentina, South America) during the early-mid 20th century. The Holocene 23: 1731-1746. https://doi.org/10.1177/0959683613505338.

Umazano, A. M., A. E. O., and S. B. Aimar. 2004. Tajamares: una tecnología alternativa para la zona árida-semiárida de La Pampa. Argentina.

UNEP. 2009. Rainwater harvesting: a lifeline for human well-being. United Nations Environment Programme.

Vivoni, E. R., E. R. Pérez-Ruiz, Z. T. Keller, E. A. Escoto, R. C. Templeton, N. P. Templeton, C. A. Anderson, A. P. Schreiner-McGraw, L. A. Méndez-Barroso, and A. Robles-Morua. 2021. Long-term research catchments to investigate shrub encroachment in the Sonoran and Chihuahuan deserts: Santa Rita and Jornada experimental ranges. Hydrological processes 35:e14031. https://doi.org/10.1002/hyp.14031.

Vohland, K. and B. Barry. 2009. A review of in situ rainwater harvesting (RWH) practices modifying landscape functions in African drylands. Agriculture, Ecosystems and Environment 131:119-127. https://doi.org/10.1016/ j.agee.2009.01.010.

Zika, M. and K.-H. Erb. 2009. The global loss of net primary production resulting from human-induced soil degradation in drylands. Ecological Economics 69:310-318. https://doi.org/10.1016/j.ecolecon.2009.06.014. 